\title{
Tooth Profile Design of Cycloid Gear Based on NC Forming Machining
}

\author{
Guixiang Liu ${ }^{1, a^{*}}$, Yan Cao ${ }^{1, b}$, Zhou Fang ${ }^{1, c}$ and Yuanyuan Kang ${ }^{1, d}$ \\ ${ }^{1}$ Department of Mechanical and Electronic Engineering, Xi'an Technological University, Xi'an, \\ China \\ a691417473@qq.com, bjantonyz@163, 27381788@qq.com, d1300796637@qq.com
}

Keywords: Cycloid gear; Profile design; Profile modification; The simulation of tooth surfaces

\begin{abstract}
In order to improve the bearing capacity and precision of cycloid gear transmission, the tooth profile of the left and right cycloid gears is taken as the theoretical cycloid tooth shape according to the principle of forming processing. By the combination of positive equidistance and positive offset, the cycloid gears are designed with tooth profile. The simulation of cycloid profiles in MATLAB environment and the establishment of cycloid model with UG software are given. The use of this program can not only improve the carrying capacity of cycloid drives and motion accuracy, but also improve the stability of transmission.
\end{abstract}

\section{Introduction}

The profile of the cycloid gear is a general designation of the cylindrical gears with various kinds of cycloid or equidistant curve. At present, the traditional methods of cycloid gear machining are milling on the use of milling cutter; vertical milling on the use of single-mode milling, but it is difficult to meet the production requirement because of the influence of the dividing error, the tooth profile error and the production efficiency [1]. Therefore, cycloid gear tooth profile design and processing is a key part of cycloid gear designs. In this paper, the stress deformation, vibration and noise of the gear is taken as the modification plan. Through the NC machining method of forming grinding, enlarge the contact area of grinding wheel and gear grinding, improve the efficiency and precision of gear form grinding.

\section{The Tooth Profiles Machining of Cycloid Gear Oriented to Forming Method}

Forming method is the method of machining the workpiece by using the cutting tool. The forming method of grinding just put the grinding wheel finishing for the shape of a workpiece contour faces anastomosis. The grinding wheel is in contact with the contour surface of the workpiece, and the whole contours are polished. Compared with other machining methods, forming method has the advantages of high precision, high efficiency, simple structure and low cost [2].

In this paper, it mainly used YK7332A gear grinding machine processing cycloid gear as an example, research on cycloid gear form grinding processing [3]. CNC grinding machine grinding method using grinding wheel, the wheel rotation, while the cycloid wheel along its own axis direction to be grinding out a tooth groove, which is grinding out a tooth on both sides of the tooth profile, the wheel back to the original position, and with the indexing device cycloid rotation $360^{\circ} / \mathrm{z}_{\mathrm{c}}\left(\mathrm{z}_{\mathrm{c}}\right.$ is the cycloid number of teeth), to continue grinding the second tooth slots. So that continuous grinding wheel can be round all the teeth. CNC grinding machine forming grinding principle and grinding logic diagram are shown in Fig. 1, Fig. 2: 


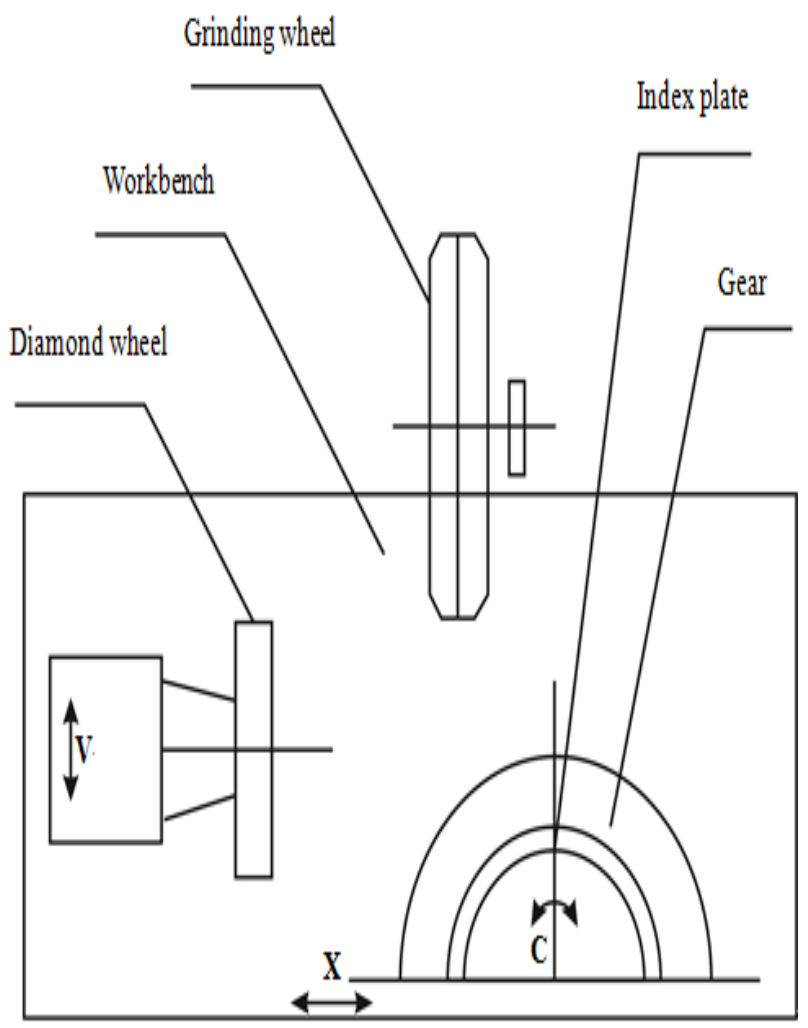

Figure 1. Forming grinding tooth principle

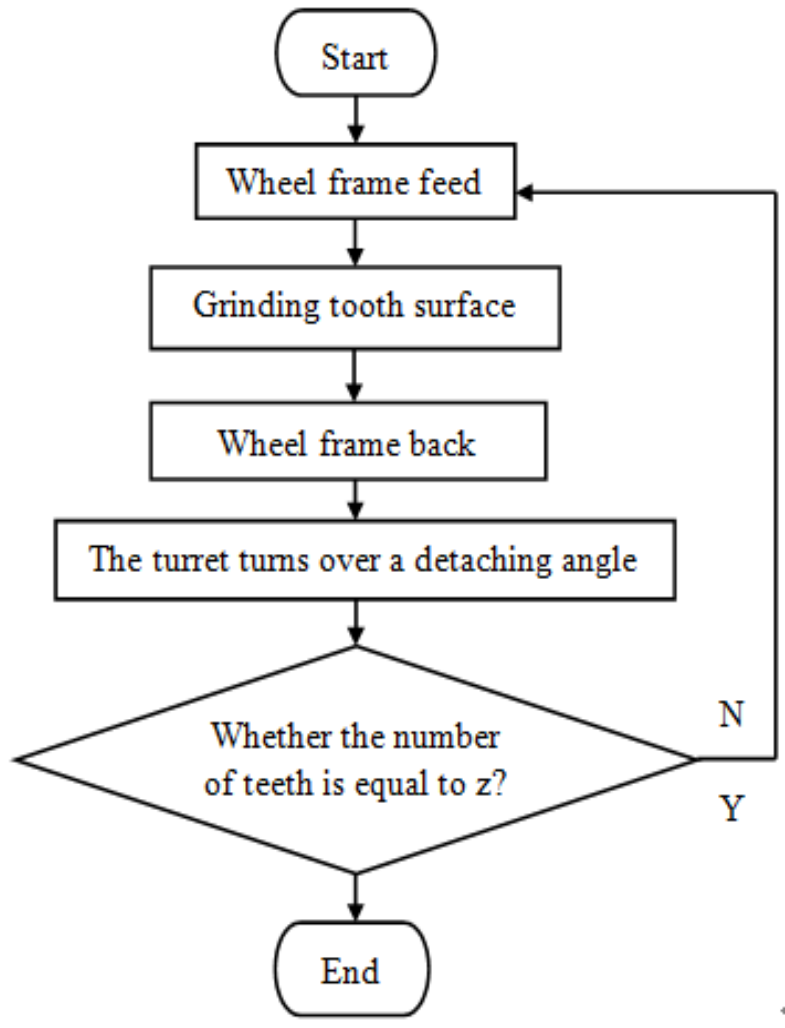

Figure 2. Grinding tooth logical diagram

\section{Design of Cycloid Gear Tooth Profile Oriented to Forming Method}

In order to improve the carrying capacity and precision of the cycloid gear transmission, the tooth profile of the cycloid gear is designed according to the forming principle [4].

(1) Because of the cycloid gear tooth top and tooth root have no effect on the transmission power, it can refer to the form of involute gear, the addendum circles and the root circle can be reduced during the roughing (milling) of the cycloid gear to produce tooth tops (bottom) clearance.

(2) In the cycloid gear processing, the moving distance and the isometric modification are used $[5,6]$.

(3) Improve the dynamic performance of gear tooth profile modification; improve the anti-gluing performance of the gear.

(4) The design tooth profile of the left and right tooth surfaces of the cycloid gear should be the theoretical cycloid profile, the gear should have the required thickness reduction.

\section{The Tooth Profiles Equation of Cycloid Gear}

Standard Tooth Profiles Equation of Cycloid Gear. The geometric center of the cycloid wheel is selected as the origin, and the axis passing through the origin and coinciding with the symmetry axis of the cycloid gear groove is taken as the axis. As shown in Fig. 3, the standard tooth equation of the cycloid gear is as follows. 


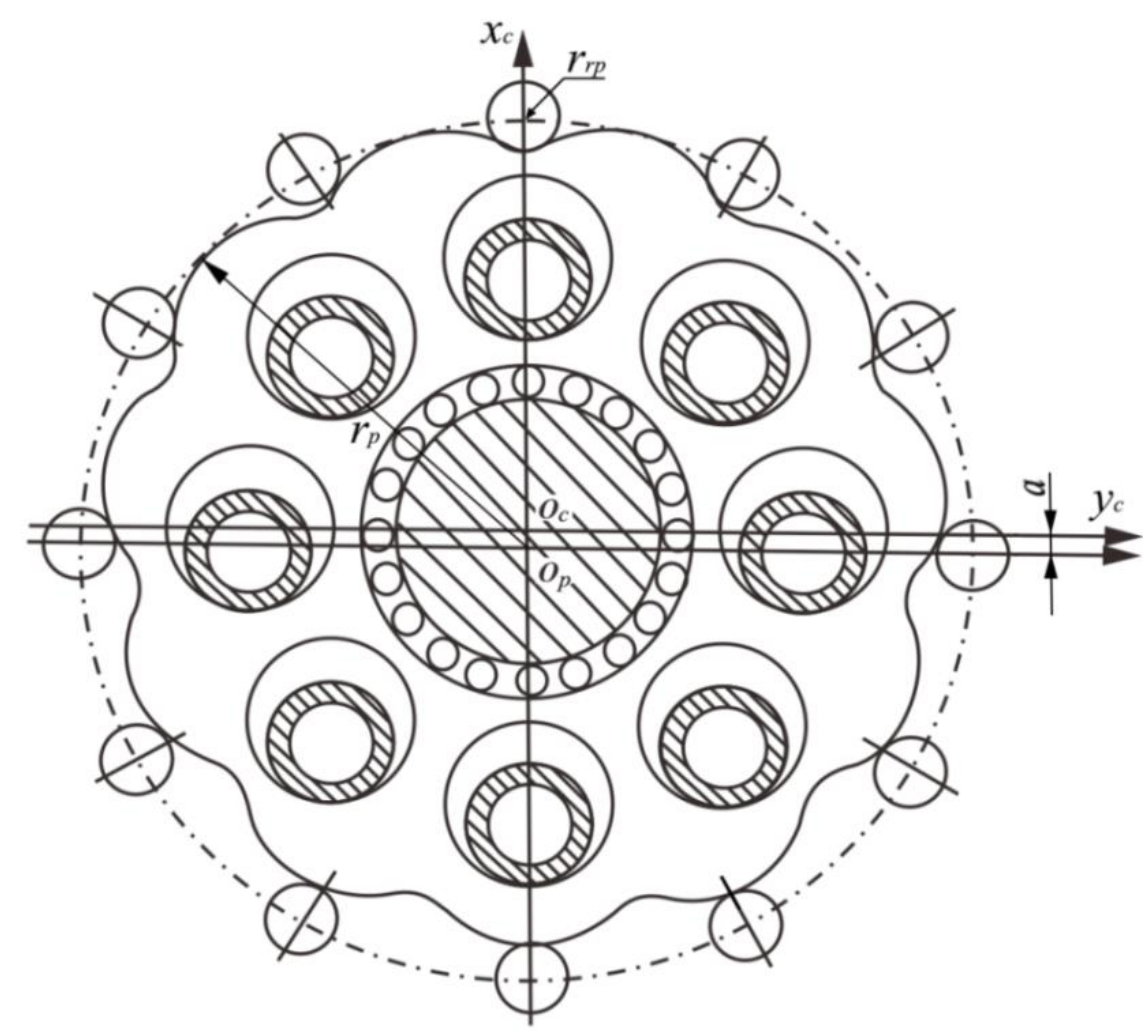

Figure 3. Cycloid transmission diagram

$$
\left\{\begin{array}{l}
x_{\mathrm{c}}=\left[r_{\mathrm{p}}-r_{\mathrm{rp}} \varphi^{-1}\left(K_{1}, \theta\right)\right] \cos \left(1-i^{\mathrm{H}}\right) \theta-\left[a-K_{1} r_{\mathrm{rp}} \varphi^{-1}\left(K_{1}, \theta\right)\right] \cos i^{\mathrm{H}} \theta \\
y_{\mathrm{c}}=\left[r_{\mathrm{p}}-r_{\mathrm{rp}} \varphi^{-1}\left(K_{1}, \theta\right)\right] \sin \left(1-i^{\mathrm{H}}\right) \theta+\left[a-K_{1} r_{\mathrm{rp}} \varphi^{-1}\left(K_{1}, \theta\right)\right] \sin i^{\mathrm{H}} \theta
\end{array}\right.
$$

In Eq. (1), $i^{\mathrm{H}}$ is the relative transmission ratio of the gear wheel and the pin wheel; $i^{\mathrm{H}}$ is equal to $\mathrm{z}_{\mathrm{p}} / \mathrm{z}_{\mathrm{c}} ; \quad \theta$ is the rotation angle of the arm relative to the center vector of a pin tooth.

$$
\begin{aligned}
& \varphi^{-1}\left(K_{1}, \theta\right)=\left(1+K_{1}^{2}-2 K_{1} \cos \theta\right)^{-\frac{1}{2}} \\
& K_{1}=a z_{\mathrm{p}} / r_{\mathrm{p}}
\end{aligned}
$$

In Eq. (1), $\quad r_{\mathrm{p}}$ is the radius of the center circle of needle; $r_{\mathrm{rp}}$ is outer circle radius of pin; $K_{1}$ is the short coefficient and $a$ is center distance.

Universal Equation of Cycloid Gears Tooth Profiles. In the practical application of the planetary gear transmission, in order to compensate the manufacturing error, easy disassembly and ensure lubrication, cycloid gear and needle teeth must be meshing between the gaps. Therefore, the actual shape of the gear tooth must be modified. Three modification methods are combined to build the profile equation of the gear [7]: 


$$
\left\{\begin{aligned}
x_{\mathrm{c}}= & {\left[r_{\mathrm{p}}+\Delta r_{\mathrm{p}}-\left(r_{\mathrm{rp}}+\Delta r_{\mathrm{rp}}\right) \varphi^{-1}\left(K_{1}^{\prime}, \theta\right)\right] \times \cos \left[\left(1-i^{\mathrm{H}}\right) \theta-\delta\right]-} \\
& \frac{a}{r_{\mathrm{p}}+\Delta r_{\mathrm{p}}}\left[r_{\mathrm{p}}+\Delta r_{\mathrm{p}}-z_{\mathrm{p}}\left(r_{\mathrm{p}}+\Delta r_{\mathrm{p}}\right) \varphi^{-1}\left(K_{1}^{\prime}, \theta\right)\right] \times \cos \left(i^{\mathrm{H}} \theta+\delta\right) \\
y_{\mathrm{c}}= & {\left[r_{\mathrm{p}}+\Delta r_{\mathrm{p}}-\left(r_{\mathrm{rp}}+\Delta r_{\mathrm{rp}}\right) \varphi^{-1}\left(K_{1}^{\prime}, \theta\right)\right] \times \sin \left[\left(1-i^{\mathrm{H}}\right) \theta-\delta\right]+} \\
& \frac{a}{r_{p}+\Delta r_{p}}\left[r_{\mathrm{p}}+\Delta r_{\mathrm{p}}-z_{\mathrm{p}}\left(r_{\mathrm{p}}+\Delta r_{\mathrm{p}}\right) \varphi^{-1}\left(K_{1}^{\prime}, \theta\right)\right] \times \sin \left(i^{\mathrm{H}} \theta+\delta\right)
\end{aligned}\right.
$$

In Eq. (2), $K_{1}^{\prime}$ is the short coefficient of tooth shape with distance shaping.

$$
\begin{aligned}
& K_{1}^{\prime}=\frac{a z_{\mathrm{p}}}{r_{\mathrm{p}}+\Delta r_{\mathrm{p}}} \\
& \varphi^{-1}\left(K_{1}^{\prime}, \theta\right)=\left(1+{K_{1}^{\prime}}^{\prime 2}-2 K_{1}^{\prime} \cos \theta\right)^{-1 / 2}
\end{aligned}
$$

In Eq. (2), $\Delta r_{p}$ is the amount of offset modification, $\Delta r_{\mathrm{rp}}$ is the isometric modification, $\delta$ is the amount of corner modification, the rest of the symbols and units have the same meanings as before.

\section{Simulation Modeling of Gear Tooth Surface}

According to the cycloid gear tooth profile equation described above, combined with the cycloid wheel parameters selected as the following, an example is given to demonstrate the accuracy of the proposed method and the model [8].

By referring to the "Mechanical design manual", the design parameters of a series of cycloid gears are selected as follows. The radius of the center circle of needle is $109 \mathrm{~mm}$; the outer circle radius of pin is $13 \mathrm{~mm}$; the tooth number of needle wheel is 12 ; the tooth number of cycloid gear is 11 ; the center distance is $7.3 \mathrm{~mm}$; the short coefficient is 0.8 ; the transmission ratio is $12 / 11$; the amount of offset modification is $0.1641 \mathrm{~mm}$; the amount of isometric modification is $0.375 \mathrm{~mm}$.

In this paper, based on the surface equations of cycloid gears, the coordinates of tooth surface modeling points of cycloid gears is solved by MATLAB software. Finally, the three-dimensional model of cycloid gears is established with UG software. The specific process is described as follows:

(1) According to the standard tooth surface equation of the cycloid gear, the design parameters of the cycloid gear are substituted into the tooth surface equation, a series of tooth surface modeling coordinate points are solved. Finally, these discrete tooth surfaces coordinate points are used to establish the standard tooth profile of the cycloid by MATLAB.

In the actual cycloid wheel drive, in order to ensure cycloid and pin gear teeth to form a certain gap between the meshing, it is need for tooth profiles to be modified. After considering the modification, the modified parameters of the cycloid wheel are added to the tooth surface theoretical equation to obtain a series of tooth surface modeling points. And then the shape of the modified cycloid gear tooth surface is constructed based on the modified discrete tooth surface coordinate points in MATLAB environment. The standard cycloid gear profile and modified cycloid gear tooth profile were compared, as shown in Fig. 4. 


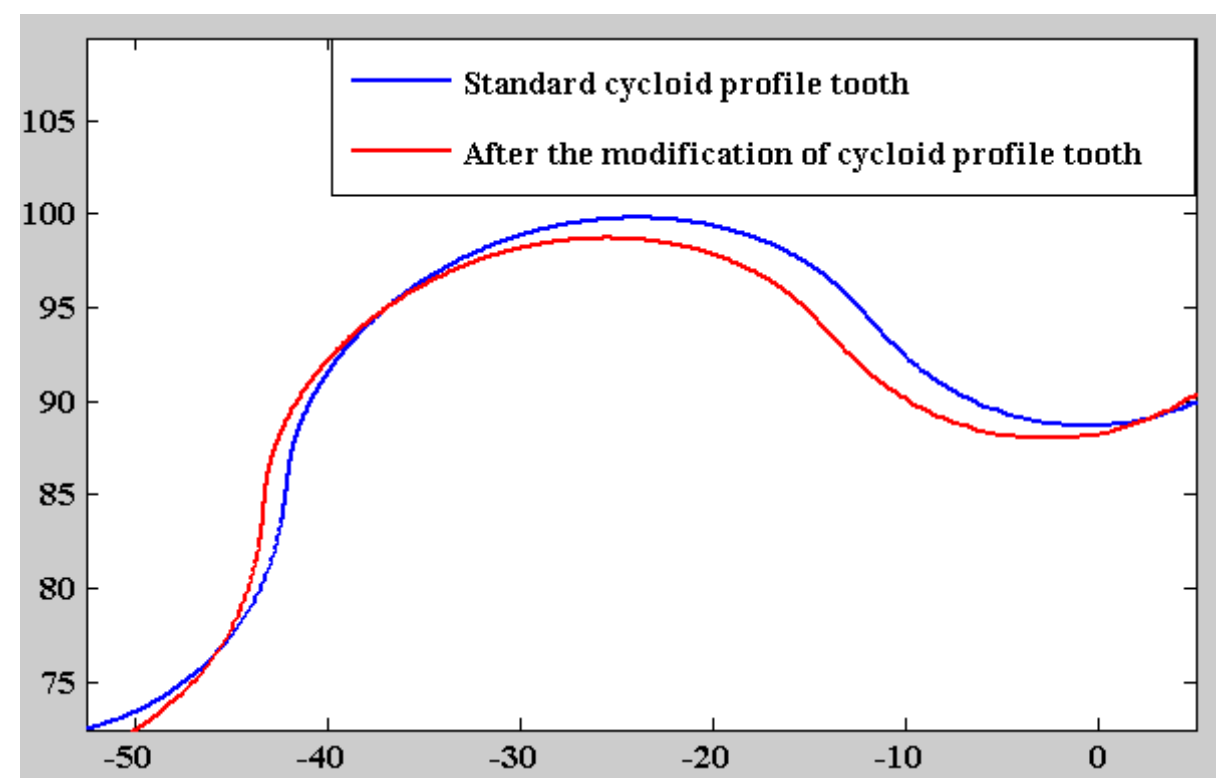

Figure 4. Standard tooth profile and modified cycloid profile contrast chart

The theory and examples show that the tooth profile can be smoothed more smoothly by the modification of the cycloid profile, and the tooth working portion and the corner modification profile can be approximated to the maximum extent, thus has the advantages of conjugate tooth smooth transmission and more meshing teeth [9].

(2) Input the coordinates of the tooth surface of the modified cycloid gears into notepad and save it in the format of ".Txt"; import the discrete tooth surface points into UG software by UG "Point in file" commands; And then the corresponding spline curve of the tooth surface is constructed by point-by-point selection using the interpolation spline curve of the "Art spline" commands.

(3) The three-dimensional model of the modified cycloid gear is established by UG software according to the coordinates of the discrete tooth surface points of each tooth surface line [10], as shown in Fig. 5.

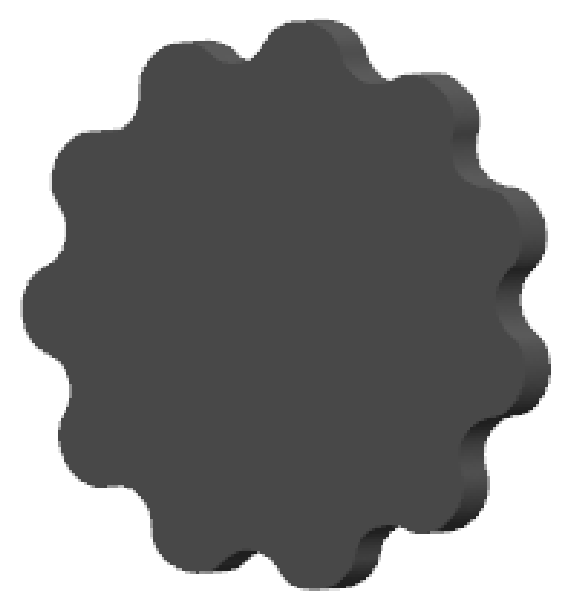

Figure 5. Three-dimensional model of cycloid gears after modification

\section{Conclusion}

Based on the tooth surface equation of the cycloid gear, by analyzing the forming principle, the tooth surface modification method with the combination of positive offset and slightly positive 
offset is used to realize the optimal design of cycloid gear tooth profile, which effectively improves the stability of transmission and motion accuracy. By using MATLAB to simulate the tooth profile of the cycloid gear, the data point in MATLAB is exported to the data point file needed for UG modeling, and the three-dimensional model of the cycloid gear is established by using the reverse engineering method.

\section{Acknowledgements}

The paper is supported by Key Laboratory Project of Shanxi Province (15JS041), project name "Research on key technology of multi axis NC combined machining of straight tooth surfaces gear."

\section{References}

[1] H.P. An: Cyclic Gear Machining by Relief Principle and Its Structural Design [J]. Mechanical Research and Application, Vol. 20 (2007) No.1, p.65. (In Chinese)

[2] H.L. Wang, Y.Q. Xiong and G.Q. He: Grinding Force Model of Grinding Helical Gear by Using Forming Method [J]. Mechanical Transmission, Vol. 39 (2015) No.4, p.49. (In Chinese)

[3] J. Han, Q.Y. Yang, K.B. Zhang and L. Xia: Geometric Error Modeling and Compensation of CNC Forming Wheel Grinding Machine [J]. Journal of Hefei University of Technology (Natural Science Edition), Vol. 35 (2012) No.12, p.1585. (In Chinese)

[4] W.X. Yao, Y.S. Tan and C.Y. Zhang: A Tooth Profile Design of Cycloid Gear [J] .Technology, Vol. 36 (2002) No.3, p.34. (In Chinese)

[5] J.B. Guo, X. Wang, H.J. Liu and Z. Li: Measurement of Cycloid Gear Error and Its Modification [J]. Journal of Tianjin University, Vol. 44 (2011) No.1, p.85. (In Chinese)

[6] W.R. Jiao, Q.H. Kong, D.C. Song, J.L. Liu and Z.W. Qin: Study on Profile Modification of Shaped Grinding Cycloid Gear [J]. China Mechanical Engineering, Vol. 20 (2009) No.22, p.2676. (In Chinese)

[7] J.Z. Liu: New Cycloid Gear Tooth Profile Design Research (MS., Harbin Institute of Technology, China 2013), p.28. (In Chinese)

[8] H.W. Wang: Design and Research of the Gear Reducer with New Short Epicycloid Gear (MS., Harbin Institute of Technology, China 2014), p.38. (In Chinese)

[9] L.N. Xing: Parametric Design and Software Development of Cycloid Drive (MS., Chongqing University, China 2010), p.24. (In Chinese)

[10]X.P. Liang: The Parameterization Design of Helical Gears Based on UG Software [J]. Technical Transmission, Vol. 33 (2009) No.2, p.47. (In Chinese) 